\title{
Bilateral Shoulder Dislocation and Unilateral Fracture of the Humeral Head: A Case Report
} Bilateral Posterior Omuz Çıkığı ve Ünilateral Humerus Başı Fraktürü; Olgu Sunumu

Şahin Çolak, Mehmet Özgür Erdoğan, Hayati Kandiş

Department of Emergency Medicine, Haydarpaşa Numune Training and Research Hospital, Istanbul, Turkey

\section{ABSTRACT}

Introduction: Although shoulder dislocations are common dislocations, posterior dislocations of the shoulder with fracture are rare. Seizures are the most common etiology for posterior dislocations. Diagnosing posterior dislocations is challenging in emergency departments. For this reason, emergency department physicians might not evaluate musculoskeletal injuries correctly. In addition, $x$-rays are not diagnostic for posterior dislocations. Late diagnosis may lead to humerus head necrosis, major complications, and malpractice.

Case Report: Our patient, who was brought due to electrical shock, had bilateral posterior dislocation and unilateral humeral head fracture.

Conclusion: In this case report, we evaluated a patient with bilateral posterior dislocation.

Keywords: Electric shock, posterior dislocation, fracture, x-ray, tomography

Received: 23.11.2013 Accepted: 30.01.2014

\section{ÖZET}

Giriş: Omuz çıkıkları sık görülen çıkıklar olmasına rağmen kırık birlikteliğinde posterior omuz çıkıkları nadir görülür. Posterior çıkıkların etyolojisinde en sık konvülsiyonlar nedendir. Posterior çıkıkların acil serviste teşhisi zordur. Bu nedenle acil hekimi kasiskelet yaralanmalarını doğru değerlendiremeyebilir. Ek olarak röntgenler posterior çıkıklarda tanı koydurucu değildir. Geç teşhis humerus başı nekrozu, major komplikasyonlara ve malpraktise neden olabilir.

Olgu Sunumu: Elektrik çarpması ile acil servise getirilen olgumuzda bilateral posterior çıkık ve ünilateral humerus başı fraktürü mevcuttu.

Sonuç: Bu olgu sunumunda çift taraflı omuz çıkığı ve tek taraflı humerus başı kırığı olan hastada röntgen filmlerinin yetersizliği ve tomografinin etkinliği değerlendirilmiştir.

Anahtar Kelimeler: Elektrik çarpması, posterior çıkık- kırık, direkt grafi, tomografi

Geliş Tarihi: 23.11.2013 Kabul Tarihi: 30.01.2014

\section{Giriş}

Elektrik çarpmalarına bağlı yaralanmalar acil serviste nadir görülmektedir ve multisistemik yaralanmalara ek olarak kas-iskelet yaralanmaları da görülebilmektedir. Bu yaralanmalar kııı, çıkık, derin dokularda yanık, motor ve duyusal sinir yaralanmasını kapsamaktadır (1). Daha önceki yayınlarda elektrik çarpmasına bağlı omuz çıkıkları ve kırıkları bildirilmiştir (2-5). Elektrik çarpmasına bağlı bilateral posterior omuz çıkıkları ise nadirdir ve özellikle posterior kııılı-çıkıklar daha az sıklıkla $(<\% 1)$ görülmektedir (1). Bu vakaların acil serviste tanınması zordur ve direkt grafiler yanıltıcı olabilir. Bu hastalarda geç tanı konması humerus başı nekrozuna neden olabilir ve bu medikal ve hukuksal ciddi sonuçlar doğurabilir. Posterior çıkıklarda fizik muayene bulguları ve görüntüleme silik olabilir. Klinik şüphe halinde hastaların tomografi ile değerlendirilmesi erken tanı için önemlidir (4).

Bu olgu sunumu; elekrtik çarpmasına bağlı posterior omuz çıkığı, tek taraflı humerus başı fraktürü görülebileceğine, direk grafinin tanı da yetersiz kaldığına ve klinik şüphe durumunda hastaların mutlaka erken tanı için tomografi ile değerlendirilmesi gerektiğine dikkat çekmek için yapıldı. 


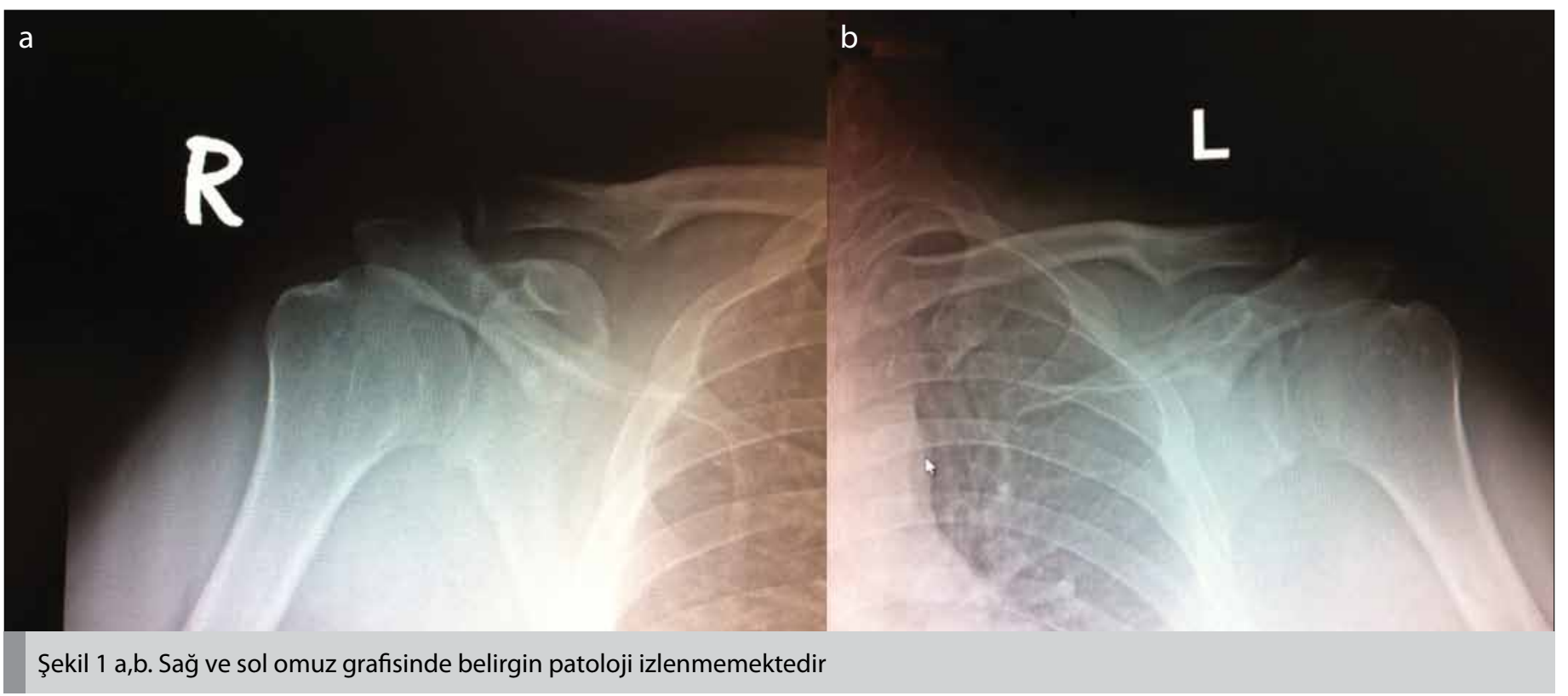

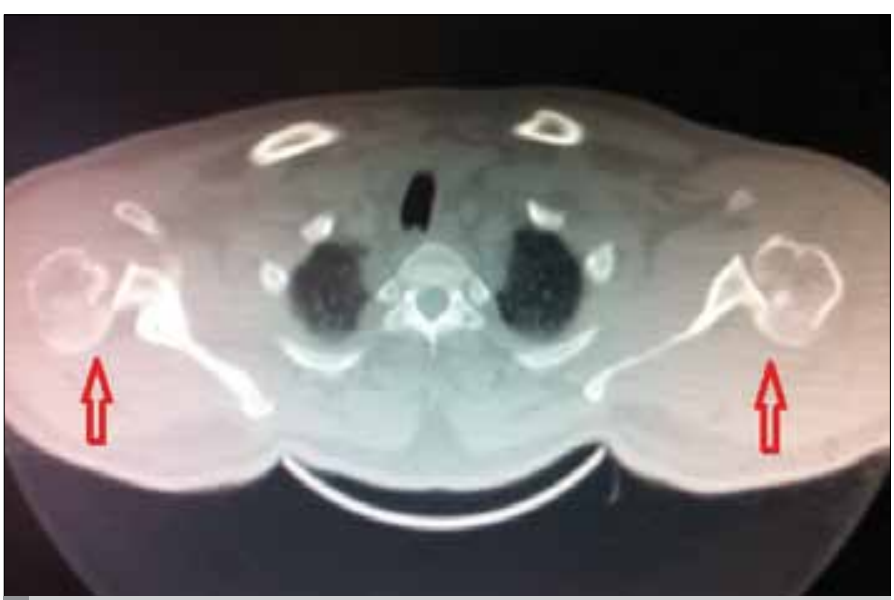

Şekil 2. Bilateral posterior omuz çıkığı ve sol humerus başında lineer fraktür görülmektedir

\section{Olgu Sunumu}

Kırk üç yaşında erkek hasta elektrik çarpması nedeniyle acil servise getirildi. Hasta evinin balkonunda elektrik kablolarının tamiri ile uğraşırken elektrik çarpmasına (220 V alternatif ev akımı) bağlı olarak balkon demirine her iki eli birlikte asılı kalmıştı. Hasta acil servise getirildiğinde fizik muayenesinde sağ el 2. distal phalanxta $0,5 \mathrm{~cm}$ (giriş noktası) ve sol ayak topuğu üzerinde $0,5-1 \mathrm{~cm}$ (çıkış noktası) üçüncü derece elektrik yanığıyla uyumlu cilt lezyonu vardı. Her iki omuzda palpasyonla yaygın ağrı ve hassasiyet mevcuttu. Omuz hareketleri kısıtlı ve ağrılıdı. Yapılan nörolojik, vasküler ve diğer sistem muayeneleri doğaldı. Olgunun geliş ve takip EKG'si sinüs ritmindeydi. Laboratuvar sonuçlarında başlangıçta ve takip süresinde özellik tespit edilmedi. Omuz hareketlerinin kısıtlı ve ağrılı olması nedeniyle çekilen omuz grafileri (Şekil 1 a, b) normal olarak değerlendirildi. Hastanın hareket kısıtıığı ve omuz ağrısı elektrik çarpmasına bağlı kas kontraksiyonlarına bağlandı ve organ yaralanmaları açısından takibe alındı. Fakat hastanın omuz ağrısının ve hareket kısıtlılığının devam etmesi üzerine hastaya bilgisayarlı tomografi çekildi. Tomografide bilateral posterior omuz çıkığı ve sol humerus başında lineer fraktür tesbit edildi (Şekil 2) Hasta ortopedi kliniği ile konsülte edildi, her iki omuza başarılı bir şekilde kapalı redüksiyon uygulandı ve ortopedi kliniğine takip amaçlı hastanın yatışı yapıldı.

\section{Tartışma}

Omuz çıkıkları, büyük eklem çıkıkları arasında ilk sırada görülmektedir (6). En sık anterior çıkılar görülmekle birlikte posteriora olan çıkıklar tüm omuz çıkıklarının \%4'ünü, inferior çıkılar ise <\%0,5'i oluşturmaktadır. Bilateral posterior çıkılar ise posterior çıkıların $<\% 5$ 'inden daha azında görülmektedir. Posterior çıkıkla birlikte kırık görülme oranı ise <\%1 altındadır $(2,5,6)$.

Bilateral posterior çıkıların etiyolojisinde "üç E sendromu" (epilepsi, ekstremite travması, elektrik çarpması) sorumlu tutulmaktadir. En çok konvulziv nöbetler (\%50) bilateral posterior çıkıktan sorumludur ve bunun \%90'na kırık eşlik etmektedir. Elektrik çarpmaları ise bilateral posterior omuz çıkılarının <\%5'inden sorumlu tutulmaktadır $(2,5,7)$. Bizim olgumuzda elektrik çarpmasına bağlı çift taraflı posterior omuz çıkığı ve tek taraflı sol humerus fraktürü mevcuttu.

Elektrik çarpmalarına bağlı birçok dokuda etkilenmeler görülebilir. Beyin, santral sinir sistemi ve kalp dokusunda oluşan yaralanmalar ölüme neden olabilir. Koroner arter nekrozu, miyokard, nodal doku ve iletken yolların etkilenmesine bağlı ortaya çıkan aritmiler ölümün en sık nedenidir (8). Aynı zamanda elektrik çarpmasına bağlı oluşan kas-iskelet yaralanmaları geniş bir yelpaze oluşturmaktadır. Bu yaralanmalar arasında kırık, çıkık, üçüncü derece yanık, motor ve duyusal sinir yaralanmaları yer almaktadır (1). Olgumuzda ise nörolojik, vasküler ve diğer sistem muayeneleri doğaldı. Takip süresinde elektrokardiogramı sinüs ritmindeydi ve laboratuvar sonuçları normal olarak değerlendirildi. 
Posterior çıkıların tanısı genellikle zordur. Yapılan bir çalışmada postreior çıkıkların \%87'si ilk muayene de atlanmıştır. Bu tip çıkıklarda erken tanı ve reduksiyon humerus başı nekrozisi açısından önemlidir. Geç tanının başıca nedenleri arasında eksik anamnez, yetersiz fizik muayene ve direk grafi başarı oranının düşük olması gelir. Anteroposterior (AP) omuz grafisi normal olarak görülebilir veya çok hafif bulgular mevcut olabilir. Bu bulgular: humerus başının ampul görünümü, vacant glenoid işareti, ön glenoid köşe ve humerus başı arasında 6 mm»den fazla mesafenin olduğu köşe işareti, humerus başında oluşan vertikal çökme fraktürüdür $(9,10)$. Bu olguda çekilen bilateral omuz grafisinde belirgin patoloji izlenmemiştir.

Posterior çıkı oluşum mekanizması ise genellikle kas kontraksiyonunda kolun, iç rotasyon ve addukiyonu sırasında meydana gelmektedir (7). Olgumuzda balkonda elektrik kablolarının tamirini yaparken elektrik çarpmasına bağlı balkon demirinde asılı kalması ile birlikte bilateral posterior çıkığı oluşmuştu. Kolun iç rotasyonda olmaması fizik muayede belirgin olmayışı tanıyı zorlaştırmıştır.

Olgumuzda ilk muayenede her iki kolda hassasiyet, ağrı ve hareket kısıtlılığının olması üzerine AP omuz grafisi çekildi ve normal olarak değerlendirildi. Hastanın hareket kısıtlılığı ve omuz ağrısı elektrik çarpmasına bağlı oluşan kas kontraksiyonlarına bağlandı. Elektrik çarpmasına bağlı oluşabilecek komplikasyonlar açısından hasta takibe alındı. Fakat hastanın hareket kısıtıığının ve omuz ağrısının devam etmesi üzerine hastaya bilgisayarlı tomografi çekildi ve bilateral posterior omuz çıkığı, sol humerus başında lineer fraktür olduğu görüldü. Hasta ortopedi kliniği ile konsülte edildi ve ortopedi kliniğine yatırıldı.

\section{Sonuç}

Bu olgu sunumu, acil servis hekimlerinin elektrik çarpmalarında multisistemik organ yaralanmalarına odaklanmışken muskuloskleteal yaralanmaları da dikkate almaları gerektiğini; elektrik çarpmasına bağlı bilateral posterior omuz kırıklı-çıkığı görülebileceğini ve direk grafilerdeki silik bulguların kolaylıkla gözden kaçabileceği ve klinik şüphe varlığında bu hastaların bilgisayarlı tomografi ile değerlendirilmesinin erken tanı için önemli olduğunu vurgulamaktadır.

Informed Consent: Written informed consent was obtained from the patient who participated in this study.

Peer-review: Externally peer-reviewed.

Author Contributions: Concept - Ş.Ç.; Design - Ş.Ç.; Supervision M.Ö.E.; Materials - M.Ö.E.; Data Collection and/or Processing - Ş.Ç.;
Analysis and/or Interpretation - H.K.; Literature Review - Ş.Ç.; Writer - Ş.Ç.; Critical Review - H.K.

Conflict of Interest: The authors declared no conflict of interest.

Financial Disclosure: The authors declared that this study has received no financial support.

Hasta Onamı: Bu çalışmaya katılan hastadan yazılı onam alınmıştır.

Hakem Değerlendirmesi: Dış bağımsız.

Yazar Katkıları: Fikir - Ş.Ç.; Tasarım - Ş.Ç.; Denetleme - M.Ö.E.; Malzemeler - M.Ö.E.; Veri toplanması ve/veya işlemesi - Ş.Ç.; Analiz ve/veya yorum - H.K.; Literatür taraması - Ş.Ç.; Yazıyı yazan - Ş.Ç.; Eleştirel Inceleme - H.K.

Çıkar Çatışması: Yazarlar çıkar çatışması bildirmemişlerdir.

Finansal Destek: Yazarlar bu çalışma için finansal destek almadıklarını bildirmişlerdir.

\section{Kaynaklar}

1. Zümrüt M, Marçıl E. Bilateral Shoulder Injury Caused By Electric Shock. JAEMCR 2013; 4: 92-4. [CrossRef]

2. Claro R, Sousa R, Massada M, Ramos J, M Lourenço J. Bilateral posterior fracture-dislocation of the shoulder: Report of two cases. Int Shoulder Surg 2009; 3: 41-5. [CrossRef]

3. Yılmaz F, Sahin F, Dalgıc Yücel S, Oflazoglu B, Esit N, Kuran B. Bilateral shoul-der fracture dislocations and radiculopathies secondary to electrical injury (a case report). Electromyogr Clin Neurophysiol 2006; 46: 387-90.

4. Özer H, Baltacı G, Selek H, Turanlı S. Opposite-direction bilateral fracture dislocation of the shoulders after an electric shock. Arch Orthop Trauma Surg 2005; 125: 499-502. [CrossRef]

5. Yeşil O, ÖztürkTC, Çevik ŞE, Güneysel Ö. Which Comes First in Posterior Shoulder Dislocation; X-Ray or Computed Tomography. JAEMCR 2012; 3: 12-4. [CrossRef]

6. Kandiş H, Katırcı Y, Sarıtaş A, Kaya H. Luxatio Erecta Olgusu. JAEM 2009; 8: 7-8.

7. Rudzinski JP, Pittman LM, Uehara DT. Shoulder and Humerus In- juries. In Judith E, Tintinally MD, MS, Editor. Emergency Medicine. 7th ed. New York: McGraw-Hill. 2010. p.1834-38.

8. Al B, Aldemir M, Güloğlu C, Kara IH, Girişgin S. Elektrik çarpması sonucu acil servise başvuran hastaların epidemiyolojik özellikleri. Ulus Travma Derg 2006; 12: 135-42.

9. Cicak N. Posterior dislocation of the shoulder. J Bone Joint Surg Br 2004; 86: 324-32. [CrossRef]

10. Tan AH. Missed posterior fracture-dislocation of the humeral head following an electrocution injury to the arm. Singapore Med J 2005; 46 : 189-92. 